\title{
Effects of obesity on the development of uterine leiomyomata: a retrospective study of 169 women who had myomectomy in southern Nigeria
}

\author{
Babah $\mathrm{OA}^{1}$, Oluwole $\mathrm{AA}^{2}$, Afolabi BB ${ }^{2}$ \\ ${ }^{1}$ Department of Obstetrics \& Gynaecology, Lagos University Teaching Hospital, PMB 12003, Idi-Araba, \\ Surulere, Lagos, Nigeria \\ ${ }^{2}$ Department of Obstetrics \& Gynaecology, Faculty of Clinical Sciences, College of Medicine, University of \\ Lagos/ Lagos University Teaching Hospital, Lagos, Nigeria
}

\begin{abstract}
This is a retrospective study of 169 women who had myomectomy for symptomatic uterine leiomyomata in Lagos, Nigeria between January 1, 2008 and December 31, 2012. This study aimed at ascertaining the relationship between uterine leiomyomata and obesity. The patients in this series were in their reproductive age with peak incidence amongst the 35-44 years age group (57.23\% of study population). Majority of these subjects (69.16\%) were obese (BMI $\geq 25$ in this series). They were predominantly nulliparous women $(83.23 \%)$ and mostly of the middle socioeconomic class.

There was no statistical significant difference between social class and obesity, duration of symptom and preoperative uterine size, parity and pre-operative uterine size, parity and number of fibroid nodules shelled out at surgery, and between obesity and the number of fibroids shelled out at surgery.

The commonest post-operative complications were haemorrhage (42.86\%), anaemia (32.65\%), sepsis (12.24\%) and wound dehiscence (10.20\%). A statistical significant association exists between obesity and development of post-operative complications but NOT in the overall morbidity of patients with fibroids in terms of duration of hospitalization.

In conclusion, obesity does not appear to influence growth of uterine leiomyomata but impacts significantly on occurrence of post-operative complications.
\end{abstract}

Key words: Obesity, Uterine leiomyomata,.

\section{Introduction}

Lagos is a major state in Nigeria and its inhabitants are of diverse tribes, customs and life styles. Located in Lagos, are many tertiary health institutions, amongst which are the Lagos University Teaching Hospital (LUTH), Idiaraba and the Lagos Island Maternity Unit of the General Hospital, Lagos Island where this study was carried out. These hospitals have competent gynaecology units that manage a large number of gynaecological cases annually from within and outside Lagos metropolis.

Uterine leiomyomata remain a common gynaecological condition treated in most tertiary health institutions in Nigeria. It constitutes $13.4 \%$ of all gynaecological admissions in Ilorin[1], while $9.8 \%$ of all gynaecological admissions in Enugu are indicated for uterine fibroids[2]. In Enugu, it was found that uterine fibroid was the indication for $26.2 \%$ of major gynaecological surgeries[2]. Hence more needs to be known about the aetiology of this condition.

Uterine fibroids affect predominantly women in their third and fourth decades of life[1], who are mostly nulliparous; studies carried out in Ilorin and Zaria showed that of women who had uterine fibroids, $60.8 \%$ and $60.6 \%$ were nulliparous $[1,3]$. The role of oestrogen in the aetiology of fibroid explains why age and parity may be a risk factor in the development of uterine fibroid. Fibroids are known to atrophy after menopause due to the hypo-oestrogenic state induced by menopause; and it has been found to be commoner in the reproductive age group.

Obesity is thought to be a risk factor for the development of uterine leiomyomata. The explanation for this is that uterine fibroids are oestrogen sensitive and just like endometrial hyperplasia and endometrial carcinomas, there is production of oestrogen by peripheral aromatization of androgens in fatty tissues and this enhances tumour growth. Social class and lifestyle is believed to play a role in obesity, however this association is not clear cut.

The common clinical features are menstrual disorders, lower abdominal pain and/or swelling, and infertility $[1,2,3]$. In Nigeria, surgery remains the mainstay of treatment. A study in Enugu showed that $60 \%$ of patients with symptomatic uterine fibroid had myomectomy while $36.8 \%$ had hysterectomy[2]. These values were similar to findings in Zaria which showed that $62.7 \%$ of patients with symptomatic uterine fibroid had 
myomectomy while $37.3 \%$ had hysterectomy[3]. Those who had myomectomy were mainly women who were still desirous of pregnancy.

Although many studies that have been done in other parts of the world suggest a relationship between uterine fibroids and obesity, a few other studies showed negative findings i.e. no relationship between uterine fibroids and obesity. If indeed obesity is a predisposing factor to development of uterine fibroids, it may then be imperative to institute weight control or weight reduction programmes in the primary prevention of uterine fibroids.

This study aimed at ascertaining the impact of obesity on development of uterine fibroids and progression of the disease, and also to determine the influence of obesity on the post-operative morbidity of the patient following myomectomy. By and large, it will enable us determine whether or not to consider modification of life style in primary prevention of this disease.

\section{Methodology}

For this study, a 5 year retrospective study of all patients who had myomectomy from January 1, 2008 to December 31, 2012 was carried out at the Lagos University Teaching Hospital, Lagos, Nigeria, to determine the relationship between occurrence of uterine leiomyomata and obesity. All the casenotes of those who had myomectomy were retrieved from the main records of the hospitals and amongst the information extracted were the patient's age, parity, occupation, educational status, pre-operative weight, height, the pre-operative uterine size and the number of fibroid nodules retrieved at surgery. The social class of each patient was determined by merging her occupation and her educational status.

The data collected was subjected to close scrutiny and analyzed. All women with body mass index $(\mathrm{BMI})>25$ were considered obese. This cut-off value was used in categorising the subjects as being "obese" and "non-obese" for ease of comparison of findings with those obtained in other studies. The pre-operative uterine and the number of fibroid nodules shelled out at surgery were used as index for assessment of rate of growth of fibroid. These data were subjected to statistical analysis using Epi Info to determine if there is any relationship between obesity and uterine fibroids. The effects of obesity on the post-operative outcome of patients following myomectomy was also assessed.

\section{Results}

3.1. Biosocial factors in study population: A total of 169 cases of women who had myomectomy for uterine fibroids were studied. The age range of the subjects was 22-45 years with a mean age \pm S.E.M of $35 \pm 0.36$ years. Most of these patients were in their thirties. They were mostly middle class women, with $72(42.9 \%)$ being in social class III and $37(22.0 \%)$ being social class IV. Most of these women with uterine leiomyoma were of low parity, $83.2 \%$ being nullparous (Table I). Over $2 / 3$ of the study population were obesed (body mass index, BMI $\geq 25$ ). The mean body mass index (BMI) of the study population was $27.4 \mathrm{~kg} / \mathrm{m}^{2}$ (Fig. 1).

3.2. These variables (social class, obesity, parity, pre-operative uterine size and number of fibroid nodules shelled out at myomectomy) were subjected to statistical analysis to see if there is any association between them and the findings were as follows:

i. There was no statistically significant association between social class and obesity $\left(x^{2}=1.8038, p=\right.$ 0.7718 )

ii. There was no statistically significant association between duration of symptom and pre-operative uterine size $\left(x^{2}=22.1533, \mathrm{p}=0.5701\right)$.

iii. There was no statistical significant difference between parity and pre-operative uterine size $\left(\varkappa^{2}=\right.$ 23.7130, $\mathrm{p}=0.0960)$.

iv. There was no statistical significant difference between age and the number of fibroid nodules shelled out at myomectomy $\left(x^{2}=94.8181, \mathrm{p}=0.2908\right)$.

v. There was no statistical significant difference between parity and the number of fibroid nodules shelled out at myomectomy $\left(x^{2}=18.8712, \mathrm{p}=0.2754\right)$.

vi. There was no significant difference between obesity and number of fibroid nodules $\left(x^{2}=3.1164, p=\right.$ $0.5385)$.

3.3. Co-morbid effects of obesity in relation to uterine leiomyomata: Of the 169 cases studied, $49(28.99 \%)$ had post-operative complications. Of these, $83.78 \%$ were obesed. Table II below shows the post-operative complications that occurred following myomectomy in these patients.

3.4. Influence of age on the development of uterine leiomyomata in the study population: The diagnosis rate of uterine fibroids according to age was highest in the third decade of life ( fig. 2). There is a low prevalence of fibroids in extremes of reproductive age.

3.5. Association between obesity and post-operative complications: A statistical analysis of the relationship between obesity and the development of post-operative complications showed that there was statistical significance between these two variables $\left(x^{2}=19.0324, p=0.0399\right)$. It was however found that there was no 
Effects of obesity on the development of uterine leiomyomata: a retrospective study of 169 women

statistically significant relationship between obesity and overall post-operative morbidity in terms of duration of hospitalization after myomectomy $\left(\boldsymbol{x}^{2}=1.1078, \mathrm{p}=0.7752\right)$.

Table I: Biosocial characteristics of patients with uterine leiomyoma

\begin{tabular}{cc}
\hline BIOSOCIAL CHARACTERISTICS & FREQUENCY (\%) \\
\hline AGE GROUP (years) & $3(1.8 \%)$ \\
$\mathbf{2 0}-\mathbf{2 4}$ & $27(16.3 \%)$ \\
$\mathbf{2 5}-\mathbf{3 0}$ & $58(34.9 \%)$ \\
$\mathbf{3 1}-\mathbf{3 5}$ & $61(36.7 \%)$ \\
$\mathbf{3 6}-\mathbf{4 0}$ & $16(9.6 \%)$ \\
$\mathbf{4 1}-\mathbf{4 5}$ & $1(0.6 \%)$ \\
$\mathbf{4 4 5}$ & $166(100.0 \%)$ \\
Total & \\
SOCIAL CLASS & $15(8.9 \%)$ \\
I & $33(19.6 \%)$ \\
III & $72(42.9 \%)$ \\
IV & $37(22.0 \%)$ \\
V & $11(6.5 \%)$ \\
Total & $168(100 \%)$ \\
$\mathbf{0}$ & \\
$\mathbf{1}$ & $139(83.2 \%)$ \\
$\mathbf{2}$ & $15(9.0 \%)$ \\
$\mathbf{3}$ & $6(3.6 \%)$ \\
$\mathbf{4}$ & $4(2.4 \%)$ \\
Total & $3(1.8 \%)$ \\
& $167(100.0 \%)$ \\
\hline
\end{tabular}

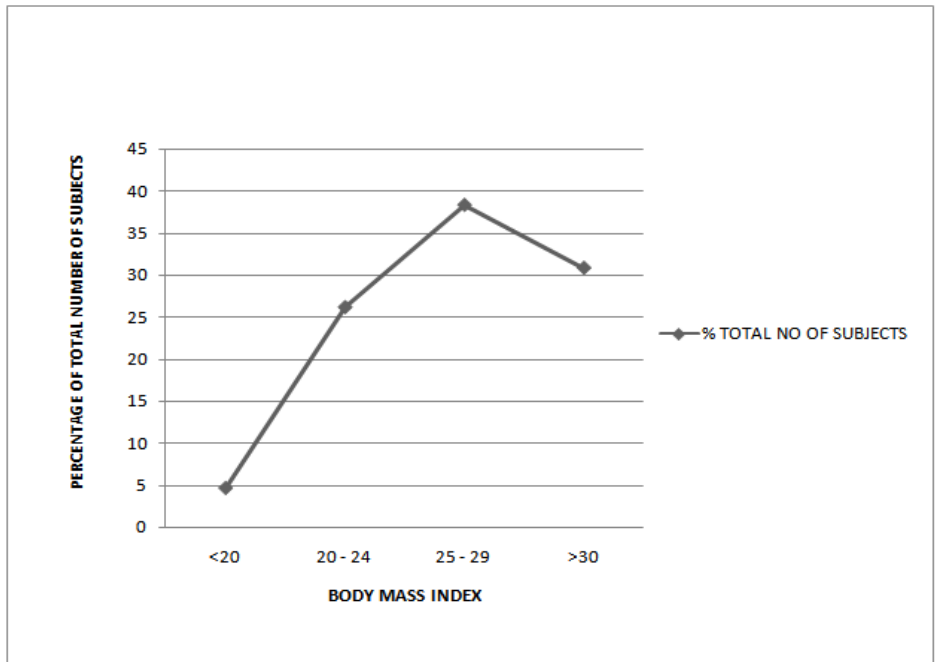

Figure 1: Diagnosis rate of uterine leiomyomata based on body mass index of subjects

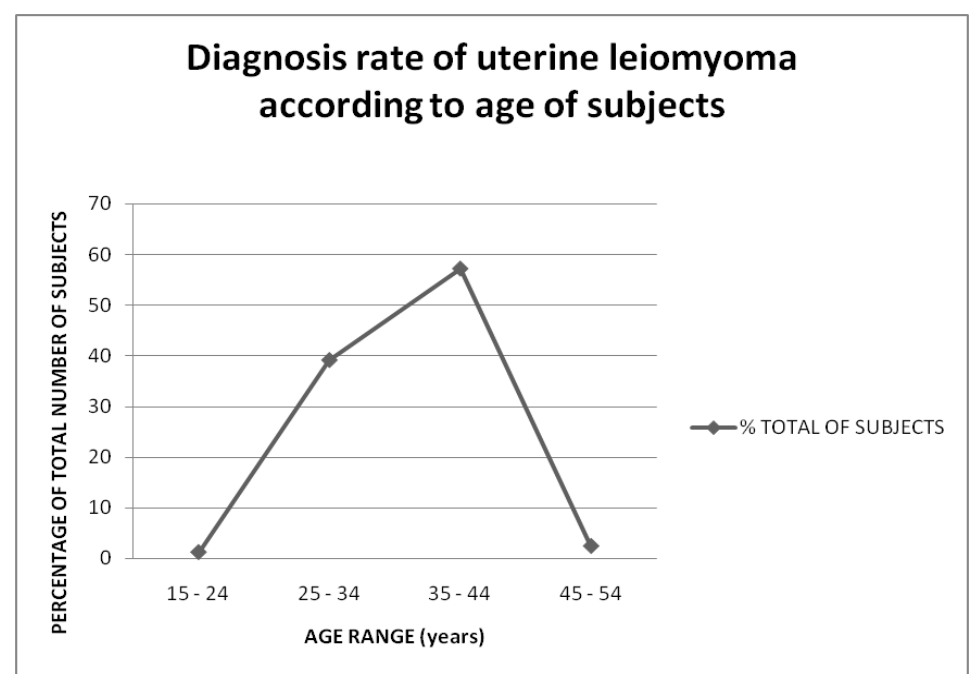

Figure 2: Diagnosis rate of uterine leiomyomata according to the age of subjects 
Table II: Pattern and incidence of post-operative complications following myomectomy

\begin{tabular}{cc}
\hline POST-OPERATIVE COMPLICATIONS & FREQUENCY(\%) \\
\hline Anaemia & $16(32.65 \%)$ \\
Haemorrhage & $21(42.86 \%)$ \\
Wound dehiscence & $5(10.20 \%)$ \\
Sepsis & $6(12.24 \%)$ \\
Urinary tract infection & $1(2.04 \%)$ \\
TOTAL & $49(100 \%)$ \\
\hline
\end{tabular}

NOTE: Of those who had anaemia, one developed anaemic heart failure. Of those who had haemorrhage, one developed disseminated intravascular coagulopathy (DIC); and amongst those who had wound dehiscence, one resulted in a burst abdomen. However, these post-operative complications were effectively managed as none of the women in this series died.

\section{Discussion}

Uterine leiomyoma is the commonest gynaecological benign tumour in our environment and a lot is yet to be known about its aetiology[4]. Amongst its aetiological factors is the role of steroid hormones such as oestrogen and progesterone[5].

Obesity has been found to play an important role in the elevation of oestrogen levels through the aromatization of androgens in adipose cells[5]. This biochemical mechanism has also been used to explain the aetiology of other disease states such as endometrial hyperplasia and endometrial carcinoma, which are influenced by high level of circulating oestrogens[6]. Obesity may be a result of genetic susceptibility, increased availability of high energy foods or reduction in physical activity (especially in modern society)[7].

This study was carried out to determine the relationship between obesity and development of uterine leiomyomata. It was found that the diagnosis of uterine fibroids increase with age through the reproductive years, with lower incidence in extremes of reproductive life. This pattern is similar to findings obtained in earlier studies carried out in other parts of the world[8,9]. According to most studies, the diagnosis rate of uterine fibroid decreased by $42-90 \%$ after menopause[10,11], this is because the hypo-oestrogenic state conferred by menopause causes atrophy of uterine fibroid resulting in a reduction in the tumour volume and size.

In this study, most of the subjects were middle class women, of low parity ( $83.2 \%$ being nulliparous) and most were in their third decade with a mean age of $35 \pm 0.36$ years. It was also found that social class does not correlate with the body mass index (BMI) of the study population.

A comparison of the variable factors showed that there was no statistically significant association between parity and pre-operative uterine size; and that the number of fibroid nodules did not correlate with the age, parity and body mass index (BMI) of the study population. This is similar to findings in a study carried out at the New England Deaconess Hospital, Harvard Medical School, Boston, Massachusetts. This study also showed that there is no significant relationship between the pre-operative uterine size and the duration of symptoms.

Although most studies have shown increased risk of fibroids in the obese (BMI >24) [12], this study, like a few others carried out in other parts of the world, has dispelled this belief [13]. It was however found that obesity is a risk factor to the development of post operative complications. In this study, $83.78 \%$ of those who developed post operative complications were obese. This did not however significantly affect the duration of hospitalization.

\section{Conclusion}

Although this study does not support the widespread belief that obesity influences the growth of uterine leiomyomata, it showed that obesity is a risk factor to the development of post operative complications and obesity may thus affect morbidity and mortality in patients undergoing surgeries. It should thus be considered as a major contributor to ill health. Modification of life style may only be necessary in controlling obesity but not in curtailing development of uterine leiomyomata.

\section{Acknowledgement}

We wish to express our sincere appreciation to all members of staff of the theatre and records departments of the Lagos University Teaching Hospital (LUTH), Lagos for granting us unrestricted access to the records used in carrying out this study. 


\section{References}

[1] Aboyeji AP, Ijaiya MA. Uterine fibroids: a ten-year clinical review in Ilorin, Nigeria. Niger J Med. 2002; 11(1): 16 - 9.

[2] Okezie O, Ezeugwu HU. Management of uterine fibroids in Enugu. Nigeria. Journal of Obstetrics and Gynaecology. 2006; 26(4): $363-365$.

[3] Mohammed A, Shehu SM, Ahmed SA, Ahmed SA, Mayun AA, Tiffin IU, et al. Uterine leiomyomata: a five-year clinicopathological review in Zaria, Nigeria. Nigerian Journal of Surgical Research. 2005; 7(1\&2): $206-208$.

[4] Takeda T, Sakata M, Isobe A, Miyake A, Nishimoto F, Ota Y, et al. Relationship between metabolic syndrome and uterine leiomyomas: A case-control study. Gynecol Obstet Invest. 2008; 66(1):14-17.

[5] Rein MS, Barbieri RI, Friedman AJ. Progesterone: a critical role in the pathogenesis of uterine myomas. Am J Obstet Gynecol. 1995; 172(1): 14-18

[6] Shikora SA, Niloff JM, Bisrian BR, Forse RA, Blackburn GL. Relationship between obesity and uterine leiomyomata. Nutrition. 1991; 7(4): 251-5.

[7] Peter G. Kopelman. Obesity as a medical problem. Nature. 2000; 404: 635-643.

[8] Wilcox LS, Komin LM, Pokras R, Strauss LT, Xia Z, Peterson B. Hysterectomy in the United States. Obstet Gynecol. 1994; 83(4): 549-55.

[9] Ross RK, Pike MC, Vessey MP, Bull D, Yeates D, Casagrande JT. Risk factors for uterine fibroids: reduced risk associated with oral contraceptives. Br Med J. 1986; 293: 359-62.

[10] Romiscu I, Walker AM, Jick S. Determinantion of uterine fibroids. Post Market Surveil. 1991; 5:199-233.

[11] Samadi AR, lee NC, Flanders WD, Boring JR, Parris EB. Risk factors for self-reported uterine fibroids: a case control study. Am J Public Health. 1996; 86: 858-62.

[12] Parazzini F, Negri E, La Vecchia C, Chatenoud L, Ricci E, Guarrero P. Reproductive factors and risks of uterine fibroids. Epidemiology. 1996; 7(4): 440-2

[13] Chen CR, Buck GM, Courey NG, Perez KM, Wactawski Wende J. Risk factors among women undergoing tubal sterilization. Am J Epidermiol. 2001; 153:20-6. 